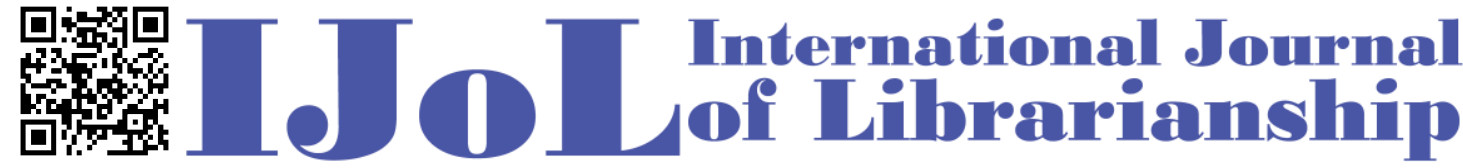

ISSN: 2474-3542 Journal homepage: http://journal.calaijol.org

\section{The Experience of International Students at Cross-Border University Libraries}

\section{Karen Bordonaro}

\begin{abstract}
:
This article describes the results of a small research study investigating international student library use and perceptions in a cross-border setting. The graduate degree program at the center of this study is a binational joint degree M.A. program in Canadian-American studies that takes place simultaneously at Brock University in Canada and at the State University of New York at Buffalo in the United States. The students' library use was explored as were their perceptions of the two different university library systems. Results indicate that students in such joint degree programs do make use of cross-border university libraries and that they see benefits in doing so. This suggests that these library settings offer librarians a unique but viable way of working with international students, and that cross-border university libraries are worthy of both mention and further study in librarianship.
\end{abstract}

To cite this article:

Bordonaro, K. (2017). The experience of international students at cross-border university libraries. International Journal of Librarianship, 2(2), 46-61.

https://doi.org/10.23974/ijol.2017.vol2.2.20

To submit your article to this journal:

Go to http://ojs.calaijol.org/index.php/ijol/about/submissions 


\title{
The Experience of International Students at Cross-Border University Libraries
}

\author{
Karen Bordonaro \\ Brock University, St Catharines, ON, Canada
}

\begin{abstract}
This article describes the results of a small research study investigating international student library use and perceptions in a cross-border setting. The graduate degree program at the center of this study is a binational joint degree M.A. program in Canadian-American studies that takes place simultaneously at Brock University in Canada and at the State University of New York at Buffalo in the United States. The students' library use was explored as were their perceptions of the two different university library systems. Results indicate that students in such joint degree programs do make use of cross-border university libraries and that they see benefits in doing so. This suggests that these library settings offer librarians a unique but viable way of working with international students, and that cross-border university libraries are worthy of both mention and further study in librarianship.
\end{abstract}

Keywords: international students, academic libraries, cross-border, Canada, United States

\section{INTRODUCTION}

Cross-border university libraries serve as a fascinating place for librarians to study international students. Cross-border, as used in this article, refers to movement across a defined international boundary between countries, such as the border between the United States and Canada. A binational setting such as the United States-Canada border supports a form of international library practice that is not widely evident in librarianship literature. The border is what defines international students here.

This article flows from the cross-border setting of the United States and Canada. It offers the results of a small research project done to explore library use and perceptions of its affiliated international students. Results from this study indicate that cross-border university libraries offer a viable place for librarians to work with international students, and that this unique setting deserves greater recognition in librarianship. 


\section{Background Setting}

The research project being described in this article took place at the Brock University library in southern Ontario that serves as the Canadian library in a joint Canadian-American Studies graduate Master of Arts (M.A.) program that began in the fall of 2013. Its American counterpart is the State University of New York at Buffalo library located in Western New York that serves as the American partner in this joint degree program.

Brock University serves approximately 18,000 students, including full-time, part-time, undergraduate, and graduate students. It is a public university founded approximately 50 years ago that was initially established as a teaching institution dedicated to the needs of undergraduate students. In the last 15 years or so, its mission has widely expanded to serve graduate students as well, at both the master's degree level and the doctoral level. This particular M.A. program is one of 49 graduate programs currently being offered by the university.

The State University of New York at Buffalo serves approximately 30,000 students, including full-time, part-time, undergraduate and graduate students. It is now a public university, serving as the flagship campus of the state university system, but it was originally founded as a private university in 1846. It has long been considered a graduate level research university, with this joint M.A. program currently being one of 300 graduate programs being offered by the university.

The library research project being reported on in this article reflects only the Canadian side of this cross-border university partnership because it was conducted as an initial exploratory study. Since the author works at the Canadian university, it made the most sense to begin this investigation from this side. The results listed below and their interpretations, then, flow principally from Canadian perspectives of this joint degree program. The author would like to add, however, that she is an American citizen who crosses this border every day herself to work at this Canadian university, so that bias might also be present in the findings of this study.

\section{LITERATURE REVIEW}

Library literature specifically targeting international students in cross-border university library settings appears to be non-existent. To be sure, however, a large and increasing amount of literature on international students and libraries in general is available and growing. The following section will briefly review library literature concerning international students, as well as how borders of any kind appear in librarianship literature.

International students in libraries have been studied in various and numerous ways, as has the concept of internationalization itself in libraries. A recent survey of the last 25 years of library literature offers an in-depth look at the many different ways that international students have been studied in libraries (Click, Wiley, \& Houlihan, 2017). The growing number of library studies devoted to international students seems to signal a surging interest by librarians in learning how to better understand and work with this important student user group on campus. It may speak as well to the growing attention on internationalization in higher education seen through increasing opportunities for study abroad as well as increasing supports for international students on home campuses. The concept of internationalization, now prevalent throughout higher education, has 
also been studied within the boundaries of academic librarianship as well (Bordonaro, 2013; Witt, Kutner, \& Cooper, 2015).

International students have often been investigated as a special population of library users that potentially require customized assistance (Ademoni, 2011; Hurley, Hegarty, \& Bolger, 2006; Koenigstein, 2012). Hurley et al. (2006), for example, used a case study approach to describe an information literacy project designed specifically for international students and found that "exploring and addressing the information and study needs of people from culturally diverse backgrounds" (p. 310) offered both exciting possibilities and challenges for librarians.

International students have also been studied as a target population for library outreach efforts that seek to find out how they use libraries or what their learning preferences are in terms of library instruction (Ishimura, Howard, \& Moukdad, 2007; Puente, Laverne, \& Agnew, 2009). Puente et al. (2009), for example, conducted a quantitative research study through the use of an online survey that identified both previously known difficulties using the library as well as new approaches that might be considered, such as offering library workshops in foreign native languages.

The study of international students in libraries has also often taken the form of librarians describing, advising, and advocating how best to work with them as non-native speakers (Aihong, 2009; Zhuo, Emanuel, \& Jiao, 2007) or as library users from different cultures (Liu \& Winn, 2009; Zhang, 2006). Zhang (2006), for example, describes in some detail the differences in communication styles between Eastern and Western cultures, and then offers librarians in Western cultures advice on how to improve their interactions with students from Eastern countries.

Considering particular Western aspects of higher education, such as dealing with plagiarism, is another common form of library studies related to international students (Amsberry, 2009; Chen \& Van Ullen, 2011; Gunnarsson, Kulesza, \& Pettersson, 2014). Amsberry (2009), for example, reviews the different learning backgrounds of American and Chinese students, and then outlines ways in which "academic librarians can promote appropriate textual borrowing practices through orientations, course-related instruction, workshops, web guides and tutorials, and reference services" (p. 42).

The appearance or description of borders of any kind in librarianship literature is much more circumspect than the literature related to international students and internationalization. By this I mean that "the border" is generally invoked more often as a setting where something took place, rather than as the explicit focus of the narrative or the study. Manuel (2010), for example, describes an Association of College and Research Libraries (ACRL) chapter that includes librarians from both Western New York and Ontario. The border in this case identifies the physical divide between librarians from two countries, but its focus is on the shared academic library association. In another example, Boone (2003) again invokes the border as the physical divide between Canada and the United States, but then examines the influence of American librarianship in the University of Toronto graduate library program.

Cross-border library settings beyond Canada and the United States appear occasionally in the library literature as well, as settings where library projects and programs take place between different countries. The border between Ireland and the United Kingdomappears in an article that offers librarians a description of a reader development project (Peoples \& Ward, 2007). Funding for that project came from the European Union and involved public libraries "operating in different 
countries, in communities divided by physical borders and sectarian division" (p. 218), working together to promote a culture of reading that promotes inclusion and diversity. In another border study, the border between Denmark and Germany serves as the backdrop for a work that explores provisions for material support of local history initiatives (Hancks, 2011). This article reports on the ongoing efforts of a Germany-based Danish Central Library to continue library support to the minority Danish-speaking Germans in North Germany. Also, the border between China and India appears as the locale for a report about archival exhibit exchanges (Jihua, 2015). This article describes exhibits hosted by the Shanghai Municipal Archives in other countries, such as India, to promote "cross-cultural, cross-border, and cross-industry collaboration" (p. 179) across borders between different countries.

Some library studies make use of "the border" in a more metaphorical sense. These types of studies investigate larger library issues that transcend physical and geographical borders. Willingham, Carder, and Millson-Martula (2006), for example, conducted a comparative study that invoked, but then transcended the United States-Canada border to consider larger issues around the provision and delivery of library instruction and professional development. Birch and Melvyn (2014) used the same approach to consider cross-border document delivery issues that transcend all borders. And Lee and Bolt (2016) explicitly advocate for local libraries to reach beyond their own borders to explore international partnership programs like sister libraries.

Where this study differs from the literature cited above is that it offers a border as the source of investigation rather than having a border serve as simply a backdrop to the study.

\section{METHODOLOGY}

This research study made use of a mixed method approach by including both quantitative and qualitative data. This methodology was chosen in order to obtain robust data. In other words, a summary of multiple choice answers can provide some overall information as to what participants might be thinking about a topic, but in-depth individual personal interviews can potentially supply much more information about why participants may be thinking a certain way. The quantitative data for this particular research study came from an online survey generated from Survey Monkey software, and the qualitative data came from in-person interviews that were conducted afterwards.

The research questions that were being investigated included:

1. Do students and faculty in joint programs like Canadian-American Studies make use of cross-border university libraries, and if so, in what ways?

2. Do students and faculty in these joint programs feel like local library users in doing so? (As used here, "local" means feeling like a Canadian library patron at the Canadian university or feeling like an American library patron at the American university. It can refer to treatment received by library employees when visiting a library in person, as well as to any perceived differences in the application of library policies related to their use of either library. It can also refer to what resources are available locally or how to access them locally as well.) 
3. Do students and faculty feel that cross-border university libraries enhance joint programs of this type?

4. Do students and faculty in joint programs feel that cross-border university libraries supporting these programs should be more closely working together? (By "working more closely together" is meant potentially offering joint programming or having the liaison librarians at each university communicating with each other directly to answer reference questions or provide further research support).

The online survey asked these questions very directly, and offered participants multiple choice answers as well as comments boxes to record further thoughts if so desired. Measurements came from level of agreement for each multiple choice question. The inperson interviews again presented participants with this same list of questions, but then became open ended conversations. These conversations flowed from any point of interest posed by these questions that a participant wanted to discuss in any further detail or in any different way.

The online survey was distributed in February 2017 through an email message the author composed about the study that was then disseminated by the director of the CanadianAmerican Studies graduate program at Brock University. It was sent to graduate students who had been in the program at this university since 2014 with whom the director had email contact, as well as faculty members currently teaching in the program in Canada. The number of potential participants was quite small, as the program at Brock University only had five total graduate students (three Canadians and two Americans) enrolled in it at the time of the study, which was January-March of 2017.

The initial email request to participate went out to approximately 15 potential respondents, both students and faculty. It invited potential participants to complete the survey and to also contact the principal investigator if they were willing to take part in a follow-up interview. Of those who received this email invitation, 5 participants answered the online survey (4 students and 1 faculty member), and 4 participants were willing to be interviewed in person (2 students and 2 faculty members). Of the 4 participants who were willing to be interviewed, it appears that 3 of them also completed the online survey. The reason for this is that two faculty members agreed to be interviewed, but only one online survey participant indicated that they were a faculty member. Both students in the interviews voluntarily said that they had completed the online survey. Follow-up personal interviews took place in March 2017. Participation rates were $33 \%$ for the online survey and $27 \%$ for the personal interviews.

The interviews were conducted by myself as the principal investigator and each lasted 3060 minutes. The two graduate students were both Canadians, as they voluntarily told me their nationalities. One faculty member was Canadian and one faculty member was American, as both made known to me, but both were employed at Brock University in Canada. The interviews were audiotaped and transcribed by myself. Brock University's Research Ethics Board gave clearance for this research study to take place. Confidentiality was ensured by my not making use of any participant's real names or any identifying 
personal characteristics and by obtaining their permission to take notes and record the interviews before they took place.

These quantitative results are followed by the qualitative content gleaned from both the comments on the surveys as well as from the recorded words of the in-person interviews. The short analysis of each of these categories is informed by the numbers and comments collected on the online survey as well as by the words collected in the personal interviews.

\section{FINDINGS}

The findings from this research project yielded some interesting results. Participants indicated that they used cross-border university libraries, and that they felt that the cross-border setting of these university libraries spanning two countries did enhance the Canadian-American Studies program. They were not sure that collaboration between the university libraries needed to be further formalized, but they did offer suggestions for future improvement of cross-border library services in terms of personal support.

The quantitative results from the online survey appear below in Figures 1 to 6 . These figures display the topic of the question, the number of responses to each answer choice, and a simple graph offering a visual display of the answers (see Figure 1-6).

Graduate student -4

Faculty member -1

Figure 1. Affiliation of survey taker with the joint Canadian-American Studies Program

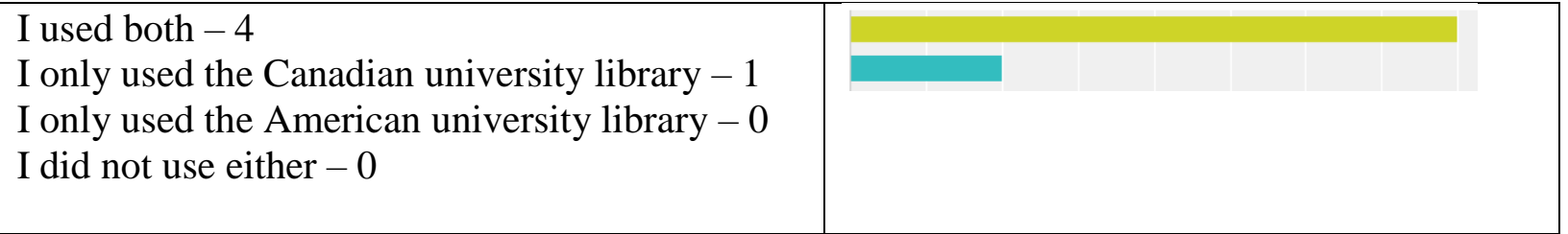

Figure 2. Library use at either or both university libraries 
Collections - to use specific print or electronic resources such as books, databases, journal articles, library guides, etc. -5

$\underline{\text { Services }}$ - to get assistance from librarians, to order materials from interlibrary loan, to check out books, to arrange library instruction classes, etc. -5

Physical Spaces - to use the physical facilities to study, meet others, do writing, for reading, etc. -4

Other - computer labs for GIS, archival resources, University Archives - 3

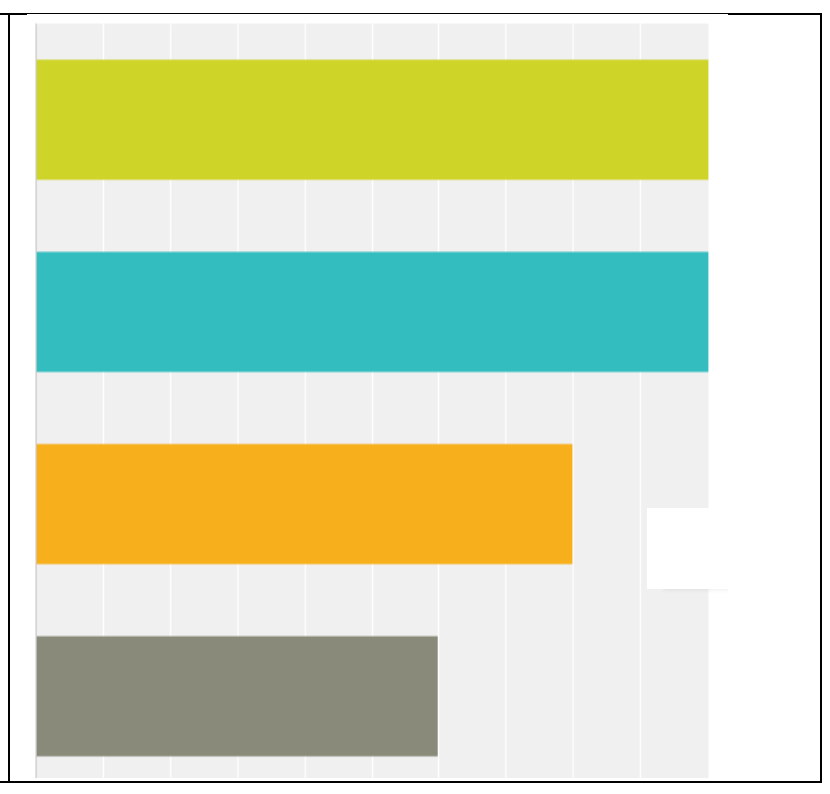

Figure 3. Type of library use

$$
\begin{aligned}
& \text { I felt like a local user at both university libraries - } 2 \\
& \text { I felt like a local user at the Canadian university - } 3 \\
& \text { I felt like a local user at the American university - } 0 \\
& \text { I did not feel like a local user at either university - } 0 \\
& \text { I cannot distinguish between feeling like a local or } \\
& \text { non-local/international library user - } 0
\end{aligned}
$$

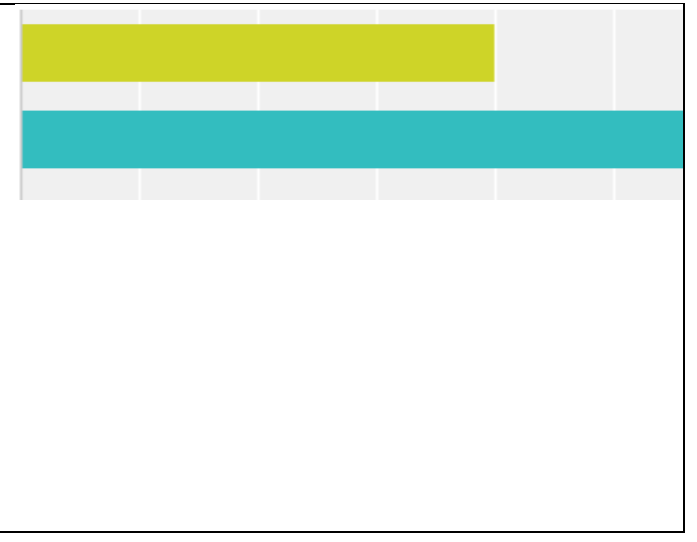

Figure 4. Feeling like a local user in terms of library policies or treatment (As used here, "local" means feeling like a Canadian library patron at the Canadian university or feeling like an American library patron at the American university)

\begin{tabular}{|l|l|}
\hline Yes -5 & \\
No -0 & \\
Not sure -0 & \\
\hline
\end{tabular}

Figure 5. Did the cross-border setting enhance this Canadian-American Studies Program 


\begin{tabular}{|l|l|l|}
\hline Yes -2 & \\
No -0 & \\
Not sure -3 & \\
\hline
\end{tabular}

Figure 6. Should the Canadian and the American university libraries work more closely together

\section{Cross-Border Library Usage}

The international graduate students and the faculty members indicated clearly that they used the cross-border university libraries. Four of the survey respondents said that they used both university libraries, while one respondent said that they only used the Canadian university library (see figure 2). After the author had an opportunity to conduct the personal interviews, she learned that the graduate students in this joint degree program had full student privileges at both the American and the Canadian university libraries, but that the faculty members in the program did not have equivalent faculty library privileges. This meant that each graduate student was issued a student ID card by both universities that allowed for these full library privileges which included signing out books and remote access to online subscription resources. Two personal follow-up interviews with faculty members confirmed this, with both indicating that they would make use of the American library resources for these courses as well as their own research if they had similar access.

Probably for this reason, the graduate students were able to make much more use of library resources, services, and spaces at both university libraries. Comments from Participant A, a graduate student, in the personal interview speak to this usage directly: "I used both libraries heavily, at least once or twice a week." Participant B, another graduate student, noted that such usage was very important at the graduate level by stating that, "As an undergraduate, I rarely used the library. As a grad student, though, the difference is like night and day."

In terms of how the cross-border university libraries were used, all of the respondents indicated that they used the collections and the services, four of five respondents noted that they used the physical spaces as well, and three respondents offered three further specialized uses. Participant C, a faculty member, confirmed in a later interview that faculty use, while restricted, the American university library's catalogue "as a finding tool" because it was freely accessible for searching, as opposed to other resources that would require a university ID for login purposes.

Collections were stressed as a key library feature supporting this joint program, with both graduate students noting that they discovered much unique material in the larger American university library that was not available at the smaller Canadian university library, as noted by Participant B: "[The American university library] is a goliath compared to what [the Canadian university library] has to offer" and "I could find American views and perspectives in their collections that I could not find here." Both faculty members concurred with this view that the American university library had a much larger and stronger research collection, with Participant $\mathrm{C}$ noting that "The [American library] resources are a compelling advantage for our grad students" and Participant D concurring that, "[This program] gives our students access to a high level research library." 
Services such as interlibrary loan were used frequently by the students, with Participant B remarking that "interlibrary loan is the best library program" and Participant A stating that many of the required textbooks for courses could be found in the circulating stacks of the American university library: "This expanded the available universe of books that could be borrowed." Checking out books was another frequently mentioned service, with Participant B remarking that, "I must have 30 books still out now." Another service mentioned by both graduate student participants as truly helpful to their studies was the minimal cost of printing at the American university library. This occurred because students there were given a larger amount of money to spend on printing, so both students said that they did all their printing on the American side for required course readings at both universities. This may not have been a direct library service, but the printers and printing paper were housed and made use of inside the library, so it was identified by both students as a library service.

Librarian research consultation service was noted by both graduate student and faculty member participants. One graduate student remarked that one month after the author had visited his class for a library instruction session, he then contacted the author for personalized follow-up help on his major research paper. Both faculty members also made use of librarian assistance through library instruction workshops offered to students in their classes for this joint degree program.

The physical spaces of both university libraries were used by the graduate students as places to study, read, wait for classes, or simply pass time. Because more time was involved in getting to the American university and staying there between classes, the students strongly identified the American library as a preferred place on campus to inhabit between classes. This time could be spent browsing the physical book collection, doing course reading, printing, or simply passing time in more personal or recreational ways.

The specialized uses of the university libraries that appeared as further comments on the survey included one mention of a geographic information systems (GIS) lab and two mentions of archive collections. GIS library workshops are offered by librarians at the Canadian university library and archives were further mentioned in the interviews as a specialized place to find unique local historical primary source materials. These examples illustrate the respondents' use of special types of materials and assistance offered by cross-border university libraries.

\section{Cross-Border Library Perceptions}

Perceptions were investigated in terms of feeling like a local user. The online survey defined "feeling like a local user" as feeling like a Canadian library patron at the Canadian university or feeling like an American library patron at the American university. This was initially intended to refer to library policies covering both Canadian and American students in the same way, as for example, book loan periods and access to resources. It could potentially also have been interpreted as cultural treatment, however, if any students or faculty felt as if their library interactions were in any way different than those of domestic users.

The strongest perception of feeling like a local library user was identified as occurring in the Canadian university library by three respondents. This is not surprising because the participants were Canadian graduate students or faculty members at a Canadian university in this joint degree program. A further two respondents on the survey indicated additionally that they felt 
like local library users at both cross-border university libraries. These were most likely students who were able to make full use of either university libraries' resources, since the faculty members did not have full access to the American university library resources.

No differing cultural treatment was noted by any of the participants on the survey or in the interviews as relating to library usage or interactions. Instead, similarities in the libraries were noted. As Participant A noted in the interview, "there are similar book arrangements in both libraries" and "the materials I needed were in the same sections in both libraries." This last comment refers to the Library of Congress Classification used in both the American and the Canadian university library. Both graduate students noted similarities in the libraries' physical set-up (book stacks, open study spaces) and the availability of both print and online resources.

Further perceptions did also arise from this study. Most related to the differing library collections. One such perception was that the necessary local history sources were much more scattered on the American side, with material dispersed between the university, the local history museum, and the public library. This was contrasted with the Canadian university, whose archives contained both regional and university historical materials. Another collection perception was that the American university library had more American sources of information and the Canadian university library had more Canadian sources of information on all topics. Evidence for this impression came from the voiced student research need for localized historical and political information from both American and Canadian perspectives.

Additional perceptions from faculty members concerned the content and nature of the program itself. One faculty member, Participant $\mathrm{C}$, perceived the program as a "double blurring of boundaries, both disciplinary and from an international perspective" that can offer students in the program a "fun, interesting, and challenging environment" in which to study. The other faculty member, Participant D, offered a further perception that student-faculty connections in this program could be "tenuous and disparate" because students could be pulled in different directions at both universities. These different directions could include different faculty areas of expertise and different interdisciplinary perspectives on both sides of the border.

\section{Enhancement and Collaboration}

All respondents to the survey indicated that the cross-border setting of the university libraries enhanced the joint Canadian-American Studies program. Their comments emphasize the importance of access to wider library collections:

"Searching for sources from a selection of texts chosen by different academic institutions increases the probability that individuals will find the sources they are searching for."

"The libraries gave me access to different collections and many of the resources I found [at the American library] were not available [at the Canadian library] and vice-versa. I definitely feel that my final MRP [major research paper] was strengthened by having access to both libraries. It was a highlight of the program for me."

The cross-border university libraries' setting offered additional enhancements to the program as well. This included a student's appreciation of access to a larger physical book collection in order to engage in "targeted browsing" of the stacks for her research. Targeted 
browsing refers to knowing where the exact physical local of print books are shelved in a library so as to find other books on the same topic nearby. This type of browsing relies on serendipity for a user to find other potentially useful books on a topic. It makes use of the online catalog as a starting point for research, but then builds in physically browsing as a way to further expand discovery of related resources.

Enhancement also included Participant C, a faculty member's perception that the students' "cross-border mobility" allowed the program to happen. This referred to the students' ability to physically drive across a national border to reach a larger university library collection. Without physically mobility, the students would not be able to engage in targeted browsing of physical library stacks, nor would they be able to attend in person any university course offered face-toface on the other campus. Physical mobility, therefore, allowed the program to take place in two different physical locales rather than take place only online.

Survey responses on whether or not the cross-border university libraries should work together more collaboratively were more muted. Two respondents said yes, but three said they did not know. The comments for this section echo this "I am not sure" sentiment, perhaps indicating that direct collaboration between the two university libraries might not be absolutely necessary.

On the other hand, suggestions for improvement of cross-border library support to individuals in the program were offered. One graduate student suggested setting up a personalized cross-border interlibrary loan program. Another graduate student suggested lowering overdue fees at the Canadian university and extending loan periods at the American university. A faculty member, Participant D, offered an intriguing suggestion for "training sessions at each library at the start of the program." The reason this comment was intriguing was because it offered a way to bring the two university libraries together in a way that had not been envisioned by librarians at either university. Faculty members at the Canadian university also indicated that access to the online journals of the American university could better support their teaching and research for the courses they offer in this program.

\section{DISCUSSION}

This research study suggests that students in joint cross-border programs can be considered international students. In this particular study, they were all native English speakers, but they were navigating two different systems of higher education simultaneously. Differences in these systems included semester lengths with different attendant beginning and ending dates, course management software, registration processes, grading expectations, and funding models for graduate student support. The uniqueness of navigating these two educational settings at the same time for this program was not lost on the students, with Participant B noting that, "We are a class of international students all on our own."

A further way that the students in this program thought of themselves as international students came from the opportunity it afforded them to think about their own personal identity. Participant B noted that he "really appreciated hearing American perspectives" because they honed his own sense of Canadianness, as well as made him feel like an international student. Participant A said that this experience gave her an expanded identity of herself as an international student that she can in turn put to good use in her new staff job in a business program: "I was an international 
student at another university. I can now say this to the Canadian students I work with in my current job." She also noted that, "You don't really know who you are until you leave the country."

The place of cross-border university libraries in joint degree programs was advocated by both the graduate students and the affiliated faculty members. The students drove across the border to take classes at both universities, and they made the most physical use of both library collections to complete their program. The faculty members supported the place of both university libraries in the joint program as well; however, Participant C remarking that, "The library piece is huge."

Limitations for this study need to be kept in mind. One limitation is the small number of participants. With only five respondents to the online survey and only four participant interviews, the data presented here can only reveal a small glimpse of what graduate students and faculty members in this joint program are thinking. In addition, with four graduate students answering the online survey as compared to only one faculty member, survey results may also be skewed to represent student perceptions more than faculty perceptions. A second limitation is that the study took place on only one side of the border. The results reported in this article can therefore only represent a Canadian perspective on the joint program and its use of library resources and services. To gain a fuller picture, a similar investigation on the American side would need to take place. The third limitation is that this study's results cannot be generalized to all students in cross-border university programs. The reason for this is that the participants in this study were not selected in a statistically randomized manner, so that they cannot be said to represent a sample of the full population of graduate students and faculty in similar programs. The perceptions of participants in this study may therefore not reflect perceptions of graduate students or faculty in other similar programs in different locations.

Implications, on the other hand, are also apparent. For university libraries interested in establishing a cross-border presence in joint programs, a number of possible implications come to mind. These include working towards making their library collections available both in person and online to students and faculty in these programs, as well as offering personalized assistance to this specialized group of users. Offering equivalent library privileges to both students and faculty members at both universities could also be considered. Student papers resulting from joint programs such as these could be considered for digitization in repositories at both university libraries. Also, articulating in writing the place of both university libraries as important partners in these ventures could be spelled out in memos of understanding designed to initially set up these types of joint degree programs between universities.

As noted in the literature review section, a body of library literature does not appear to exist that explicitly investigates cross-border university libraries as settings where international students are studied in relation to library use. This current study seeks to both highlight that gap, and then attempt to fill some of it by offering a preliminary look at the library use of international students in a joint Canadian-American Studies program.

This study can validate the use of a border between countries as a setting that is conducive to library study. In that regard, it can corroborate findings from other library studies that rely on border settings as well, such as the Ireland-UK border setting promoting reading culture across borders (People \& Ward, 2007) and the Germany-Denmark border setting that describes how the Danish central library system is still supporting minority Danish speakers in Germany with local historical material (Hancks, 2011). This study also extends consideration of the specific CanadaUnited States border that appears in the study investigating library instruction and professional 
development practices of librarians in both Canada and the United States (Willingham et al., 2006). This study may also add to worldwide cross-border library practice that invokes the crossing of borders in a larger international scope. For example, the considerations of worldwide interlibrary loan issues (Birch \& Melvyn, 2014) and worldwide partnerships between libraries (Lee \& Bolt, 2016).

Yet much further work is required to learn more about this unique set of users, the international students who use cross-border university libraries in joint degree programs. For example, a more in-depth look at how and why students in similar cross-border joint programs might consider themselves to be international students is in order. Findings from a study such as that could enrich the knowledge base of this unique setting for future library research. In addition, a deeper investigation of how students in similar programs use library resources and services over an extended length of time would also enhance our knowledge of services which support students' information needs. Finally, librarians could consider further ramifications of working with these users such as language and cultural differences that may play out differently across different borders.

\section{CONCLUSION}

Cross-border university library settings offer a viable place to explore library perspectives of a special set of international students. These students, enrolled in binational joint degree programs, represent a unique set of international students in a unique international setting.

The particular program investigated in this research study, a Canadian-American Studies graduate program, indicated that cross-border university libraries are used in various ways by these international students. These ways include accessing resources both in print and online, meeting one-on-one with librarians, and using library services such as book checkouts and interlibrary loan. Physical library spaces were used as well for browsing the stacks, reading, printing, and passing time.

Library perceptions of international students emerging from this study offer an interesting twist to the usage findings. These perceptions include feeling like a local or domestic user in both settings, while still thinking of themselves as international students. Further perceptions about collections include perceiving the differing sizes, content, and research focus of the two university libraries, while still noting similarities in physical environments, collection organization, and services.

Further perceptions from the faculty participants include the perception that the border can be discrete (physically separates two different countries), but it can also be blurred (differences are not always distinct). This blurring of differences can refer to similar content held in both university libraries as well as similar content offered in courses at both universities. Another faculty perception arising from the study is that borders can both connect students from both countries, but that it can also pull them in different directions as well. The pulling in different directions could refer to different disciplinary directions and to different perspectives within a particular discipline.

The cross-border university libraries setting was strongly endorsed by both graduate students and faculty members as enhancing the binational nature of a joint degree program. 
Providing access to two university library collections in two different countries to support students in one joint program was seen as the key form of enhancement. This enhanced access seemed to inform both the library usage and the accompanying perceptions.

This study can offer two new thoughts to the librarianship literature. It can offer the idea that cross-border students in joint degree programs can be international students. It can also offer the idea that cross-border university library settings are a viable topic of study for librarianship as well.

\section{References}

Ademoni, O. (2011). Reference service in academic libraries: Accommodation of international students. Library Philosophy \& Practice,1-10. Retrieved from http://digitalcommons.unl.edu/cgi/viewcontent.cgi?article=1555\&context=libphilprac

Aihong, F. (2009). Creating a bilingual library information environment for foreign users. The Electronic Library, 27(2), 237-246.

Amsberry, D. (2009). Deconstructing plagiarism: International students and textual borrowing practices. Reference Librarian, 51(1), 31-44.

Birch, K., \& Melvyn, T. (2014). Cross-border document delivery: The convenience and perils of sharing articles around the world, in the cloud. Interlending \& Document Supply, 42(2/3), 70-74.

Boone, E. A. (2003). Cross border influences for librarianship: The Toronto experience. Journal of Educational Media \& Library Sciences, 41(2), 163-170.

Bordonaro, K. (2013). Internationalization and the North American University Library. Lanham, MD: Scarecrow Press.

Chen, Y., \& Van Ullen, M. K. (2011). Helping international students succeed academically through research process and plagiarism workshops. College \& Research Libraries, 72(3), 209235.

Click, A. B., Wiley, C. W., \& Houlihan, M. (2017). The internationalization of the academic library: A systematic review of 25 years of literature on international students. College \& Research Libraries, 78(3), 328-358.

Gunnarsson, J., Kulesza, W. J., \& Pettersson, A. (2014). Teaching international students how to avoid plagiarism: Librarians and faculty in collaboration. The Journal of Academic Librarianship, 40(3/4), 413-417.

Hancks, J. (2011). Cross-border library services. Scandinavian Public Library Quarterly, 44(4), 24-25. 
Hurley, T., Hegarty, N., \& Bolger, J. (2006). Crossing a bridge: The challenges of developing and delivering a pilot information literacy course for international students. New Library World, 107(7/8), 302-320.

Ishimura, Y., Howard, V., \& Moukdad, H. (2007). Information literacy in academic libraries: Assessment of Japanese students' needs for successful assignment completion in two Halifax universities. Canadian Journal of Information \& Library Sciences, 31(1), 1-26.

Jihua, Z. (2015). Archival exhibitions: Cross-border cultural exchange and collaboration. Comma 2014, (1-2), 179-184.

Koenigstein, D. (2012). Alleviating international students' culture shock and anxiety in American academic libraries: Welcome, ahlan, wa sahlan, anyeong hae sae yo, bienvenidos, uan ying, sanu da zuwa, shalom, swaagat hai. Library Philosophy \& Practice Retrieved from http://digitalcommons.unl.edu/cgi/viewcontent.cgi? article=1812\&context=libphilprac.

Lee, J., \& Bolt, N. (2016). International partnerships: Value, benefits, and the library administrator's role. Journal of Library Administration, 56(3), 209-221.

Liu, G., \& Winn, D. (2009). Chinese graduate students and the Canadian academic library: A user study at the University of Windsor. The Journal of Academic Librarianship, 35(6), 565-573.

Manuel, K. (2010). Crossing borders: The Western New York/Ontario ACRL chapter. Feliciter, $56(6), 240-241$.

Peoples, A., \& Ward, T. (2007). "Inspiring Readers": A cross border reader development project. New Library World, 108(5/6), 218-228.

Puente, M., LaVerne, G., \& Agnew, S. (2009). The expanding library wall: Outreach to the University of Tennessee's multicultural/international student population. Reference Services Review, 37(1), 30-43.

Willingham, P., Carder, L., \& Millson-Martula, C. (2006). Does a border make a difference? Library instruction in the United States and Canada. The Journal of Academic Librarianship, 32(1), 23-34.

Witt, S. W., Kutner, L., \& Cooper, L. (2015). Mapping academic library contributions to campus internationalization. College \& Research Libraries, 76(5), 587-608.

Zhang, L. (2006). Communication in academic libraries: An East Asian perspective. Reference Services Review, 34(1), 164-176.

Zhuo, F., Emanuel, J., \& Jiao, S. (2007). International students and language preferences in library database use. Technical Services Quarterly, 24(4), 1-13. 
About the author

Karen Bordonaro is Liaison Librarian IV who works with students and faculty in Applied Linguistics, Canadian Studies, ESL Services, and Modern Languages, Literatures and Cultures, among other departments. Karen has degrees in Spanish and German, Library and Information Studies, Teaching English to Speakers of Other Language, and Second Language Education. 